\title{
Clinical impact of genomic characterization of 15 patients with acute megakaryoblastic leukemia- related malignancies
}

\author{
Emilie Lalonde, ${ }^{1}$ Stefan Rentas, ${ }^{1}$ Gerald Wertheim, ${ }^{1,2}$ Kajia Cao, ${ }^{1}$ Lea F. Surrey, ${ }^{1,2}$ \\ Fumin Lin, ${ }^{1}$ Xiaonan Zhao, ${ }^{1}$ Amrom Obstfeld, ${ }^{1,2}$ Richard Aplenc, ${ }^{3}$ Minjie Luo, ${ }^{1,2}$ \\ and Marilyn M. $\mathrm{Li}^{1,2,3}$

\footnotetext{
${ }^{1}$ Department of Pathology and Laboratory Medicine, Children's Hospital of Philadelphia, Philadelphia, Pennsylvania 19104, USA; ${ }^{2}$ Department of Pathology and Laboratory Medicine, ${ }^{3}$ Department of Pediatrics,
} \\ Perelman School of Medicine, University of Pennsylvania, Philadelphia, Pennsylvania 19104, USA
}

Corresponding author: lim5@chop.edu

(C) 2021 Lalonde et al. This article is distributed under the terms of the Creative Commons Attribution License, which permits unrestricted reuse and redistribution provided that the original author and source are credited.

Ontology term: acute megakaryocytic leukemia

Published by Cold Spring Harbor Laboratory Press

doi:10.1101/mcs.a005975
Abstract Acute megakaryoblastic leukemia (AMKL) is a rare subtype of acute myeloid leukemia but is approximately 500 times more likely to develop in children with Down syndrome (DS) through transformation of transient abnormal myelopoiesis (TAM). This study investigates the clinical significance of genomic heterogeneity of AMKL in children with and without DS and in children with TAM. Genomic evaluation of nine patients with DS-related TAM or AMKL, and six patients with non-DS AMKL, included conventional cytogenetics and a comprehensive next-generation sequencing panel for single-nucleotide variants/ indels and copy-number variants in 118 genes and fusions involving 110 genes. Recurrent gene fusions were found in all patients with non-DS, including two individuals with complex genomes and either a NUP98-KDM5A or a KMT2A-MLLT6 fusion, and the remaining harbored a CBFA2T3-GLIS2 fusion, which arose from both typical and atypical cytogenetic mechanisms. These fusions guided treatment protocols and resulted in a change in diagnosis in two patients. The nine patients with DS had constitutional trisomy 21 and somatic GATA1 mutations, and those with DS-AMKL had two to four additional clinically significant somatic mutations. Comprehensive genomic characterization provides critical information for diagnosis, risk stratification, and treatment decisions for patients with AMKL. Continued genetic and clinical characterization of these rare cancers will aid in improving patient management.

[Supplemental material is available for this article.]

\section{INTRODUCTION}

Acute megakaryoblastic leukemia (AMKL) is a rare subtype of acute myeloid leukemia (AML), defined by the presence of at least $50 \%$ of blasts from the megakaryocytic lineage, and patients often present with thrombocytopenia or thrombocytosis. Other clinical features include dysplastic neutrophils, erythroid cells, and germ cell tumors in young men. AMKL is typically observed in children, accounting for $4 \%-15 \%$ of AML cases, compared to $<1 \%$ of adult patients. A diagnosis of AMKL can be made if the pathognomonic $t(1 ; 22)(p 13.3$; q13.3) translocation is observed, resulting in a RBM15-MKL1 gene fusion, or by pathological assessment of bone marrow as described above. However, recent studies have shown that 
AMKL is genetically heterogeneous with distinct subgroups based on cytogenetic and molecular alterations (Hama et al. 2008; Bhatnagar et al. 2016).

Children with Down syndrome (DS) have an estimated 150- to 500-fold increased risk of AMKL compared to children without DS (Creutzig et al. 1996; Hasle et al. 2000). Somatic GATA1 mutations drive the development of transient abnormal myelopoiesis (TAM; also known as transient myeloproliferative disorder [TMD]) in utero through impaired megakaryocytic differentiation (Roy et al. 2009; Bhatnagar et al. 2016). Although most patients undergo spontaneous resolution of TAM within weeks of diagnosis, a small subset of high-risk patients presenting with life-threatening signs such as respiratory impairment, hepatic dysfunction, and/or leukocytosis (white blood cell [WBC] $>100,000$ ) may not survive (Gamis et al. 2011). A further $20 \%$ of patients with TAM will go on to develop DS-AMKL due to accumulation of additional genetic mutations and clonal expansion (Nikolaev et al. 2013; Yoshida et al. 2013).

Genetic analysis of non-DS AMKL has identified additional recurrent gene fusions in addition to the pathognomonic RBM15-MKL1 fusion. Next-generation sequencing (NGS) and targeted analysis of genes commonly altered in myeloid malignancies revealed a number of recurrent genetic rearrangements that evaded cytogenetic detection (Gruber et al. 2012; de Rooij et al. 2017). Evaluation of 89 pediatric patients with non-DS AMKL using NGS revealed an inversion on Chromosome 16 associated with a CBFA2T3-GLIS2 gene fusion in 18\% of patients, rearrangements involving KMT2A in $17 \%$ of patients, rearrangements of the HOX gene cluster in $14 \%$ patients, and a $t(11 ; 12)$ translocation resulting in a NUP98KDM5A gene fusion in $11.5 \%$ of patients (De Rooij et al. 2017). Interestingly, the pathognomonic $t(1 ; 22)(p 13.1 ; q 13.3)$ translocation is observed in only $10 \%$ of patients, and acquired GATA1 mutations, which arise in all TAM patients, are observed in $9 \%$ of patients of nonDS AMKL. In addition to the stark differences in genomic profiles between DS-AMKL and non-DS AMKL, the latter is also associated with significantly worse prognosis and higher mortality rates (Hama et al. 2008; de Rooij et al. 2016).

The recurrent genetic features carry different diagnostic, prognostic, and therapeutic implications, making comprehensive genetic testing critical for optimal patient management. We present 15 patients with AMKL-related malignancies that illustrate various clinical scenarios and genomic strategies enabling accurate diagnosis and prognostication of AMKL.

\section{RESULTS}

\section{AMKL Not Related to Down Syndrome (Non-DS AMKL)}

Six patients were diagnosed with AMKL unrelated to DS, of which five presented between 1 to $2 \mathrm{yr}$ of age, with physical symptoms including fevers, bruising, rashes, and cytopenia (Table 1). The sixth patient presented at $11 \mathrm{yr}$ of age with persistent thrombocytopenia during routine follow-up 5 yr post low-risk B-cell acute lymphoblastic leukemia (B-ALL) treatment. Given that this patient's prior therapy for B-ALL did not include any cytotoxic therapies known to be associated with therapy-related $A M L$, it was hypothesized that his AMKL may be a de novo AML, although the possibility of a therapy-related AML could not be excluded. Clinical history for all patients is summarized in Table 1. Pathological evaluation was suggestive of AMKL in four of six cases, but genetic testing was required for diagnosis in patients 1 and 3 (see Discussion).

All six patients had comprehensive genomic evaluation (Table 2; Fig. 1), including cytogenetics and comprehensive NGS analyses. Cytogenetic studies revealed multiple changes in all patients, including complex, multiclonal karyotypes in patients 1, 2, and 6 (Table 3). Only patient 4 had a cytogenetic finding highly suggestive of a non-DS AMKL-related translocation, a pericentric inversion associated with CBFA2T3-GLIS2. In contrast, in all six patients a gene fusion of diagnostic significance was detected using the NGS panel, 


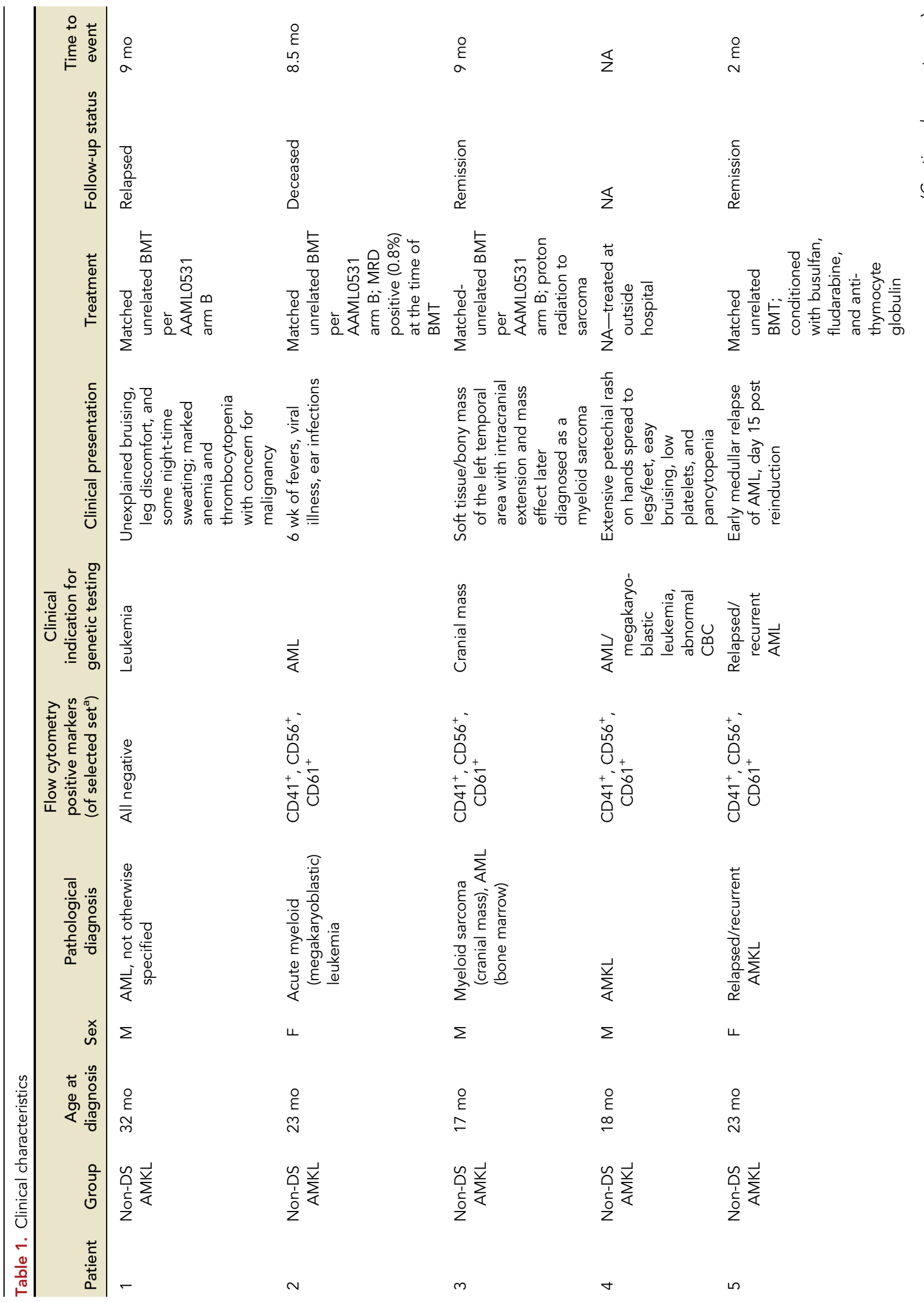




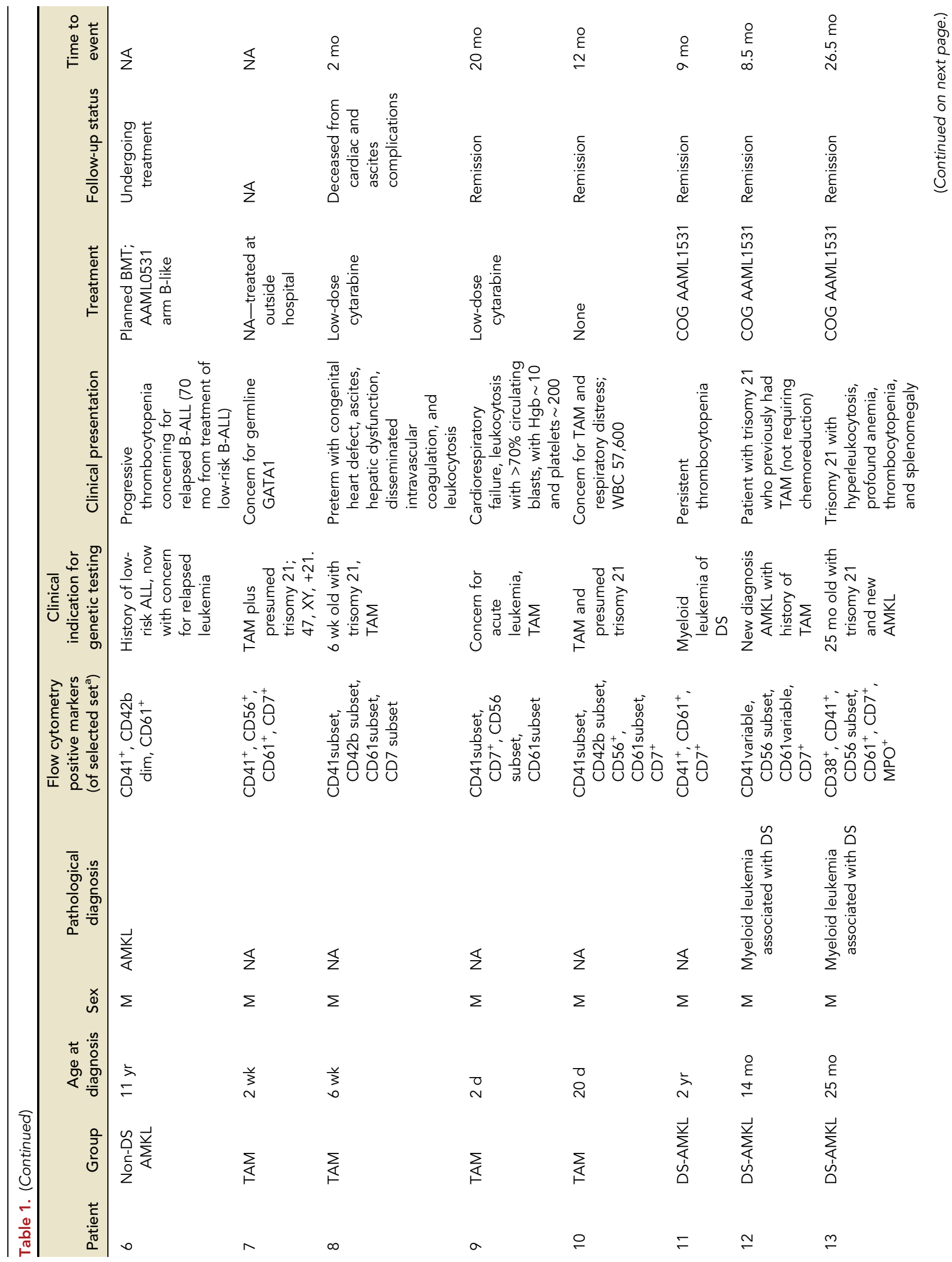




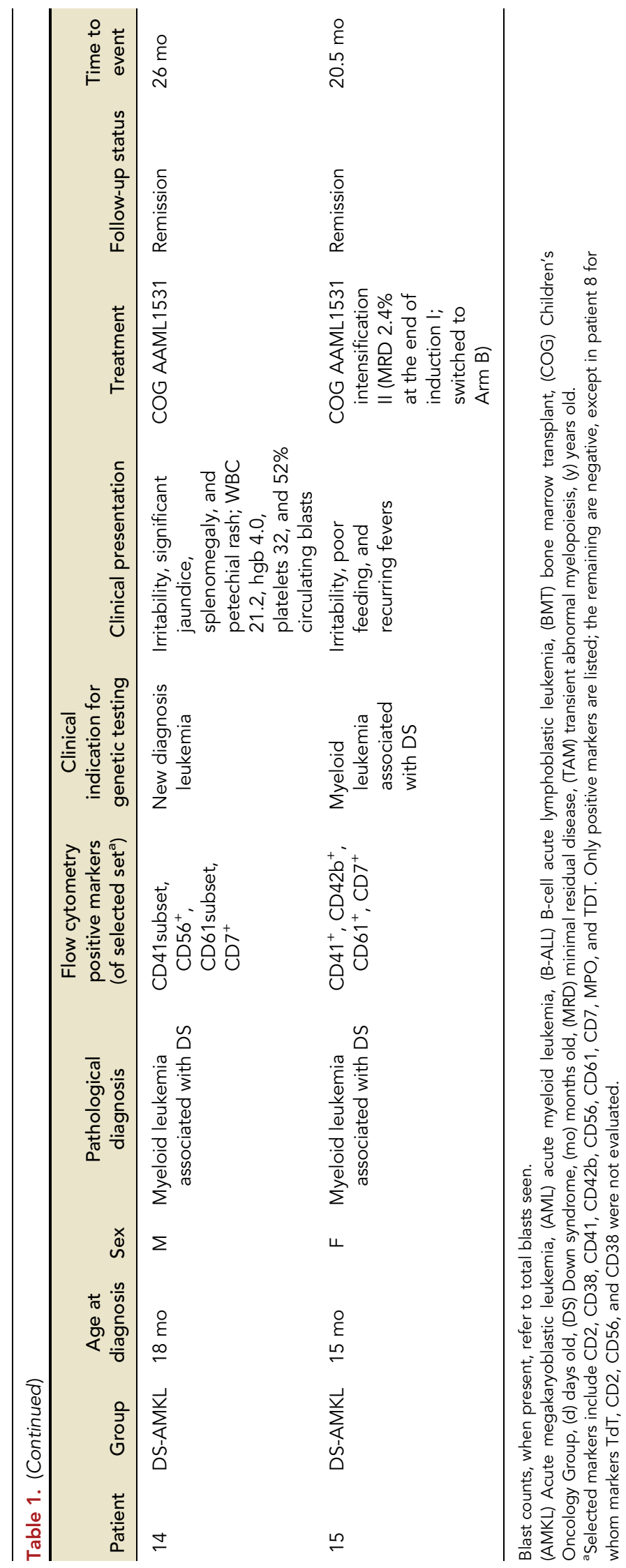




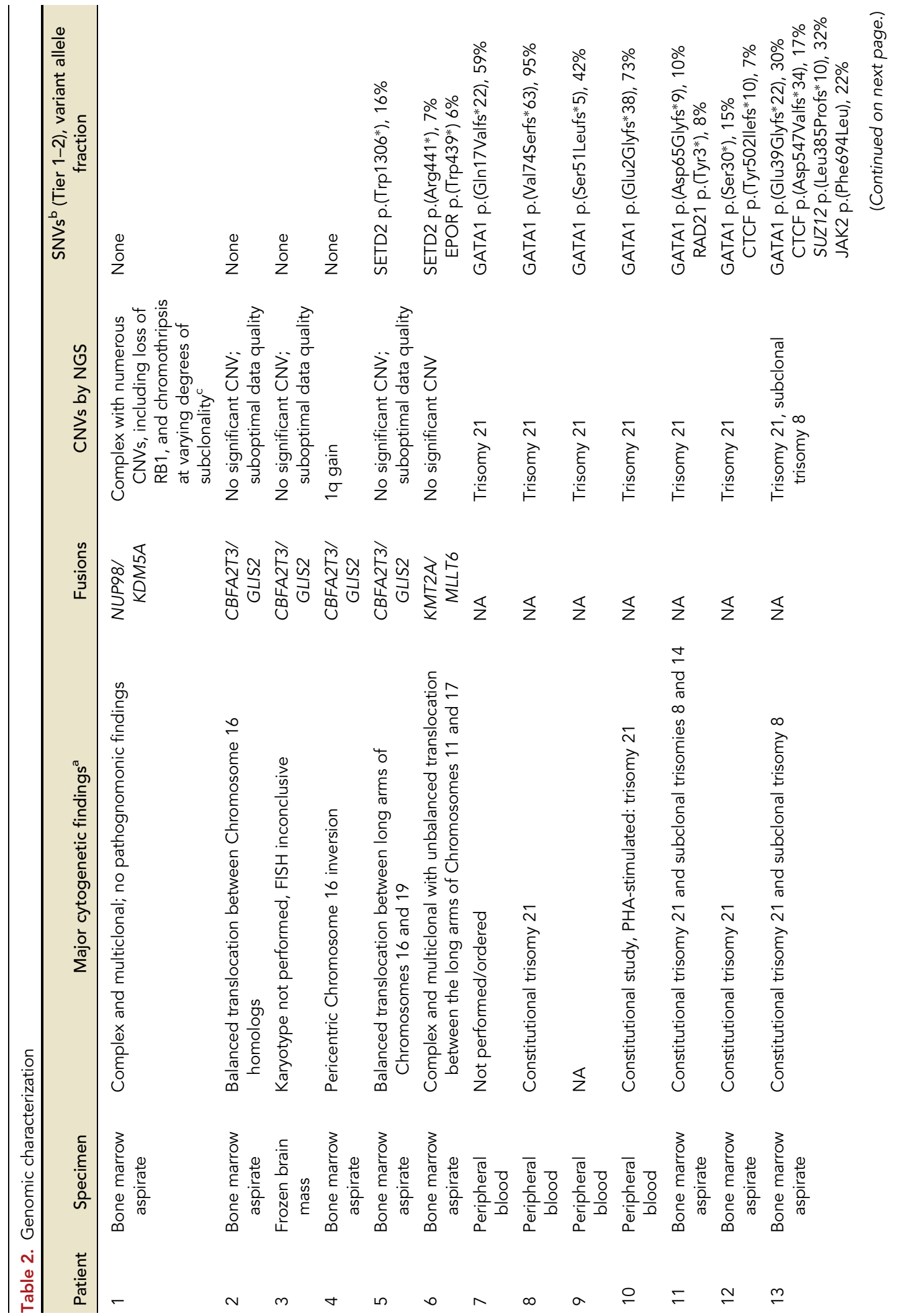




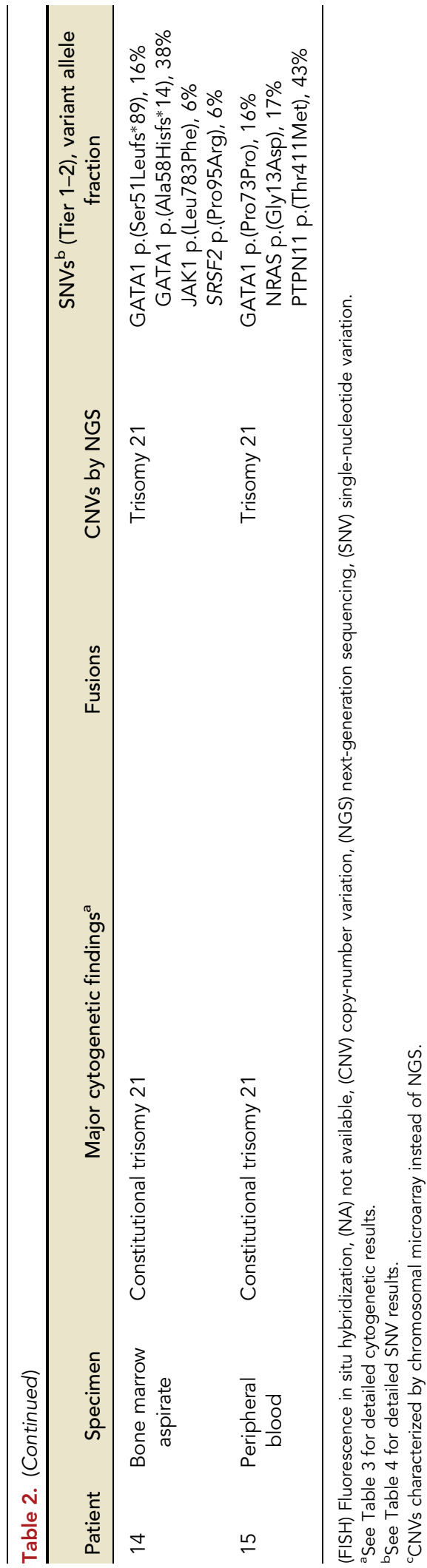


COLD SPRING HARBOR Molecular Case Studies
Genomics of acute megakaryoblastic leukemia

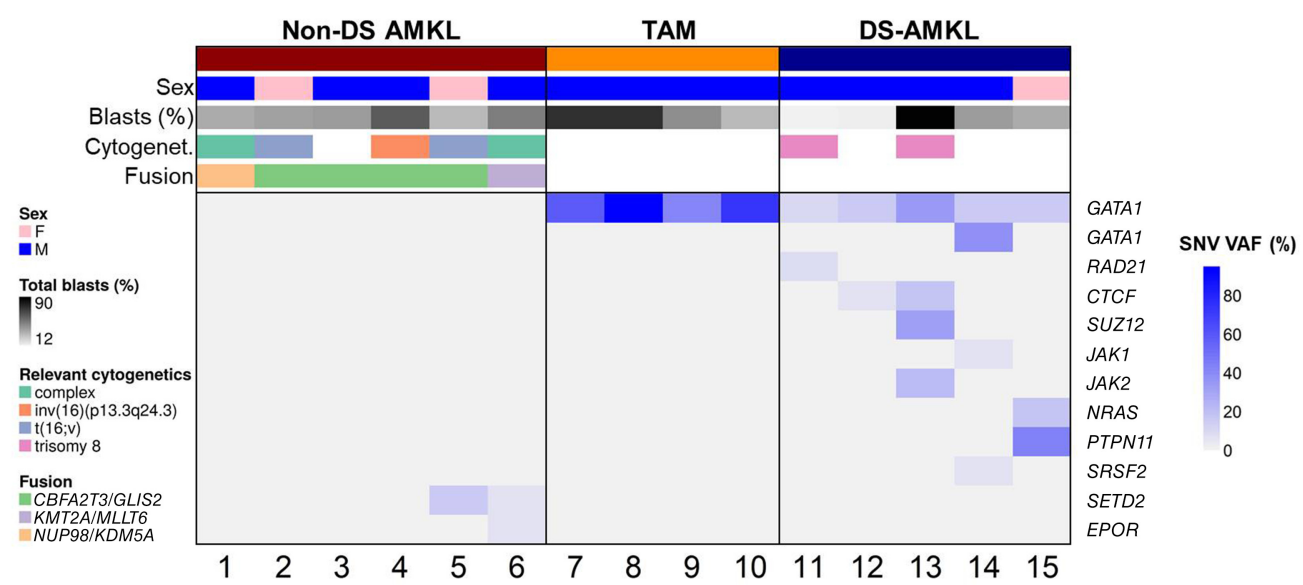

Figure 1. Genomic profile of 15 patients with acute megakaryocytic leukemia (AMKL)-related malignancies. Patients with non-Down syndrome AMKL (non-DS AMKL) are defined by recurrent gene fusions, whereas patients with transient myeloproliferative disease (TAM) have GATA1 mutations with high variant allele fraction (VAF), and patients with DS-AMKL have additional somatic variants in signaling pathway genes. Total blast percentages are based on flow cytometry. Only variants classified as Tier 1-2 are listed. See Table 2 for complete genomic profile of each individual.

including one patient with NUP98-KDM5A (Fig. 2), one patient with KMT2A-MLLT6, and four patients with CBFA2T3-GLIS2 (Fig. 3). Interestingly, only two patients had clinically significant somatic mutations, both of which were in SETD2, a methyltransferase commonly altered in leukemias, typically associated with poor prognosis and which may confer chemoresistance (Table 2; Skucha et al. 2019). Overall, the genomes of these leukemias are characterized by large structural changes resulting in often cryptic, recurrent gene fusions with a relatively low mutational burden (Fig. 1). All five patients with follow-up information available underwent bone marrow transplant because of the high-risk of relapse.

\section{Down Syndrome-Related Transient Abnormal Myelopoiesis (TAM)}

Four patients in our cohort were diagnosed with TAM and presented between $2 \mathrm{~d}$ to $6 \mathrm{wk}$ of life (Table 1). As expected, a GATA1 SNV was observed in each patient, and no fusion events were observed (Table 2; Fig. 4). The GATA1 mutations were present at high variant allele fraction (VAF), ranging from $42 \%$ to $95 \%$.

Despite similar genetic profiles, significantly different clinical outcomes were observed (clinical details not available for patient 7). Patients 8 and 9 presented with high-risk features including leukocytosis and respiratory distress and were thus treated with low-dose cytarabine according to standard protocols (Gamis et al. 2011). Patient 8 developed significant comorbidities including ascites, hepatic dysfunction, and disseminated intravascular coagulation and ultimately passed away at 3 mo of age because of multiorgan failure secondary to his complete atrioventricular canal. Patients 9 and 10 remain leukemia-free at 20 mo and 1 yr of age, respectively.

\section{Down Syndrome-Related AMKL (DS-AMKL)}

In contrast to the patients with TAM, the five patients diagnosed with DS-AMKL presented as toddlers (14-25 mo), and only patient 12 had a known prior history of TAM. Patients were treated according to the Children's Oncology Group (COG) AAML1531 protocol, and all patients remain disease-free (follow-up time 8.5-30 mo). 
Table 3. Cytogenetic findings

\begin{tabular}{|c|c|c|c|}
\hline Patient & Specimen & Karyotype & Interphase FISH results \\
\hline 1 & $\begin{array}{l}\text { Bone marrow } \\
\text { aspirate }\end{array}$ & $\begin{array}{l}\text { 47,XY,r(3)(::p12->q12::q24->q26::), del(13)(q14.1q14.3), } \\
\text { der(19)(3pter->3p12::21q11.2->21q22::19p13.3->19qter), } \\
\text { del(20)(q11.2q13.1),der(21)(21pter->21q22::19p13.3-> } \\
\text { 19p13.1::3q21->3qter),+mar[11].ish r(3)(CEP3+,EVI1+), } \\
\text { der(19)(RUNX1+,TCF3+), del(20)(D20S108-), der(21)(RUNX1+, } \\
\text { TCF3+,EVI1+)/46,sl,t(14;18) (p11.1;q11.2), -mar[5]/46,sl, } \\
\text { der(13)(?21pter->21q21::13q11.2->13q14.1::13q14.3-> } \\
\text { 13q34::13q14.3->13qter), - del(13), -mar[5] }\end{array}$ & $\begin{array}{l}\text { nuc ish }(E V I 1 \times 3)[150 / 200] \\
\text { nuc ish }(R U N X 1 T 1 \times 2, \text { RUNX1 } \times 3)[146 / 200] \\
\text { nuc ish }(T C F 3 \times 3, C E P 3 \times 2)[150 / 200] \\
\text { nuc ish }(20 \text { ptelx2,D20S108 × 1)[144/200] }\end{array}$ \\
\hline 2 & $\begin{array}{l}\text { Bone marrow } \\
\text { aspirate }\end{array}$ & $\begin{array}{l}\text { 46,XX,t(16;16)(p1?3;q2?4), der(22)t(1;22)(q10;q10)[6].ish } \\
\text { t(16;16)(16ptel++,CBFB+,16qtel-;16ptel-,CBFB+, } \\
\text { 16qtel++)/46,idem,i(17)(q10)[5]/46,XX[8] }\end{array}$ & 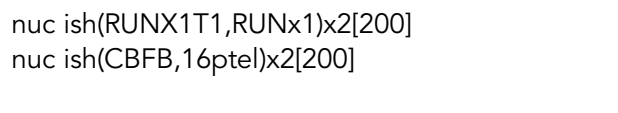 \\
\hline 3 & $\begin{array}{l}\text { Frozen brain } \\
\text { mass }\end{array}$ & Not performed/ordered & 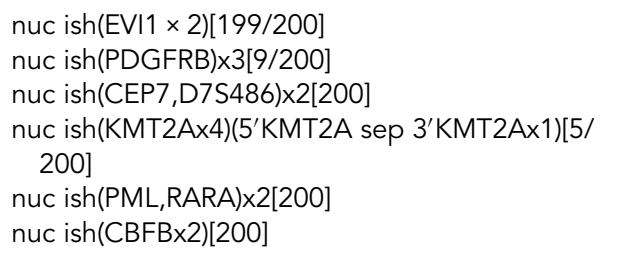 \\
\hline 4 & $\begin{array}{l}\text { Bone marrow } \\
\text { aspirate }\end{array}$ & $\begin{array}{l}\text { 46,XY,der(14)t(1;14)(q2?1;q32)[13].ish der(14)(LSI1q25+,IGH-), } \\
\quad \operatorname{inv}(16)(\mathrm{G} 248 \mathrm{P} 8680 \mathrm{H} 10+, \mathrm{CBFB}+) / 46, \mathrm{XY}[7]\end{array}$ & $\begin{array}{l}\text { nuc ish }(\mathrm{LSI} 1 \mathrm{p} 36 \times 2, \mathrm{LSI} 1 \mathrm{q} 25 \times 3)[110 / 200] \\
\text { nuc ish(CEP8 } \times 2, \mathrm{MYC} \times 2, \mathrm{IGH} \times 1)[116 / 200] \\
\text { nuc ish }(\mathrm{KMT} 2 \mathrm{~A} \times 2)[200]\end{array}$ \\
\hline 5 & $\begin{array}{l}\text { Bone marrow } \\
\text { aspirate }\end{array}$ & $\begin{array}{l}\text { 47,XX,del(7)(q2?2),?t(16;19)(q2?4;q13.?1),+21[7].ish del(7) } \\
\text { (CEP7+,D7S486-),t(16;19) (CBFB+,G248P85334F2+; } \\
\text { G248P89955D12+,G248P85334F2-)/46,XX[13] }\end{array}$ & $\begin{array}{l}\text { nuc ish }(C E P 7 \times 2, D 7 S 486 \times 1)[54 / 200] \\
\text { nuc ish }(R U N X 1 T 1 \times 2, R U N X 1 \times 3)[50 / 200] \\
\text { nuc ish }(K M T 2 A \times 2)[200] \\
\text { nuc ish(CBFBx2)[200] }\end{array}$ \\
\hline 6 & $\begin{array}{l}\text { Bone marrow } \\
\text { aspirate }\end{array}$ & $\begin{array}{l}\text { 46,XY,t(11;17)(q23;q2?1)[1]/49,idem,+2,+5,+21[6]/47,XY,der(5) } \\
\text { t(5;11)(q12;p15),der (11)t(5;11)(q12;p15)t(11;17)(q23;q2?1), } \\
\text { der(17)t(11;17)(q23;q2?1),+19[10]/46,XY[4].ish t(11;17) } \\
\text { (5'KMT2A+,3'KMT2A-;5'KMT2A+,3'KMT2A+) }\end{array}$ & $\begin{array}{l}\text { nuc ish(5'KMT2A×3, } 3^{\prime} \text { KMT2Ax2)(5'KMT2A con } \\
\text { 3'KMT2Ax2)[50/200], (ETV6 × 2, RUNX1 × 3)[38/ } \\
\text { 200] }\end{array}$ \\
\hline 7 & $\begin{array}{l}\text { Peripheral } \\
\text { blood }\end{array}$ & Not performed / ordered & NA \\
\hline 8 & $\begin{array}{l}\text { Peripheral } \\
\text { blood }\end{array}$ & $47, X Y,+21 c[19]$ & nuc ish(CBFBx2)[200] \\
\hline 9 & $\begin{array}{l}\text { Peripheral } \\
\text { blood }\end{array}$ & NA & NA \\
\hline 10 & $\begin{array}{l}\text { Peripheral } \\
\text { blood }\end{array}$ & $47, X Y,+21$ (constitutional study, PHA-stimulated) & NA \\
\hline 11 & $\begin{array}{l}\text { Bone marrow } \\
\text { aspirate }\end{array}$ & $49, X Y,+8,+14,+21 c[10] / 46, X Y,+21 c[10]$ & nuc ish(CEP8,MYC,IGH)×3[50/200] \\
\hline 12 & $\begin{array}{l}\text { Bone marrow } \\
\text { aspirate }\end{array}$ & $\begin{array}{l}\text { 47, } X Y, ? \text { del }(3)(q 21 q 25), \text { del }(7)(p 13),+21 c[16] . i s h ~ ? d e l(3)(E V I 1+, \\
\quad B C L 6+) / 47, X Y,+21 c[14]\end{array}$ & $\begin{array}{l}\text { nuc ish }(E V I 1 \times 2)[200] \\
\text { nuc ish }(B C L 6 \times \times 2)[200] \\
\text { nuc ish }(C E P 7, D 7 S 486) \times 2[200]\end{array}$ \\
\hline 13 & $\begin{array}{l}\text { Bone marrow } \\
\text { aspirate }\end{array}$ & $48, X Y,+8,+21 c[14] / 47, X Y,+21 c[7]$ & $\begin{array}{l}\text { nuc ish(RUNX1T1 × 3,RUNX1 × 3)[125/200]/ } \\
\text { (RUNX1T1 × 2,RUNX1 × 3)[75/200] }\end{array}$ \\
\hline 14 & $\begin{array}{l}\text { Bone marrow } \\
\text { aspirate }\end{array}$ & $47, X Y,+21 c[20]$ & 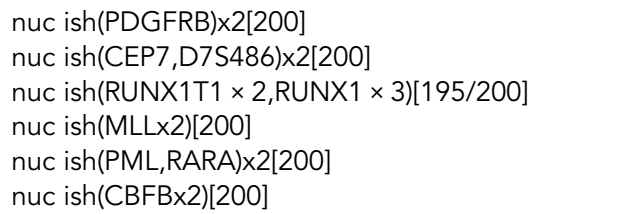 \\
\hline
\end{tabular}

(Continued on next page.) 
Table 3. (Continued)

\begin{tabular}{|c|c|c|c|}
\hline Patient & Specimen & Karyotype & Interphase FISH results \\
\hline 15 & $\begin{array}{c}\text { Peripheral } \\
\text { blood }\end{array}$ & $47, X X,+21 c[20]$ & 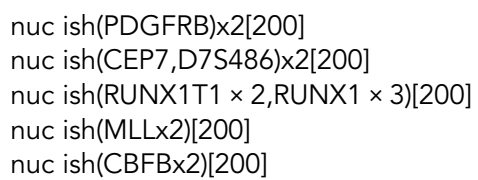 \\
\hline
\end{tabular}

(FISH) Fluorescence in situ hybridization, (NA) not applicable.

The genetic profiles in these DS-AMKL patients were distinct from patients with TAM or non-DS AMKL (Fig. 1). Although all patients had GATA1 mutations, they also had additional molecular and/or cytogenetic changes (range two to four additional changes; Table 2). Two patients had trisomy 8 , patient 12 had other cytogenetic changes, and all five patients had sequence mutations in pathways known to be involved in DS-AMKL, including two with frameshift mutations in CTCF. The other mutations involve genes in the RAS pathway (JAK1, JAK2, NRAS, PTPN11), cohesin complex (RAD21), epigenetic regulators (SUZ12), and spliceosome components (SRSF2).

\section{DISCUSSION}

In our cohort, the three groups of patients displayed distinct genomic profiles (Fig. 1). NonDS AMKL is characterized by large cytogenetic changes, often with complex genomes,
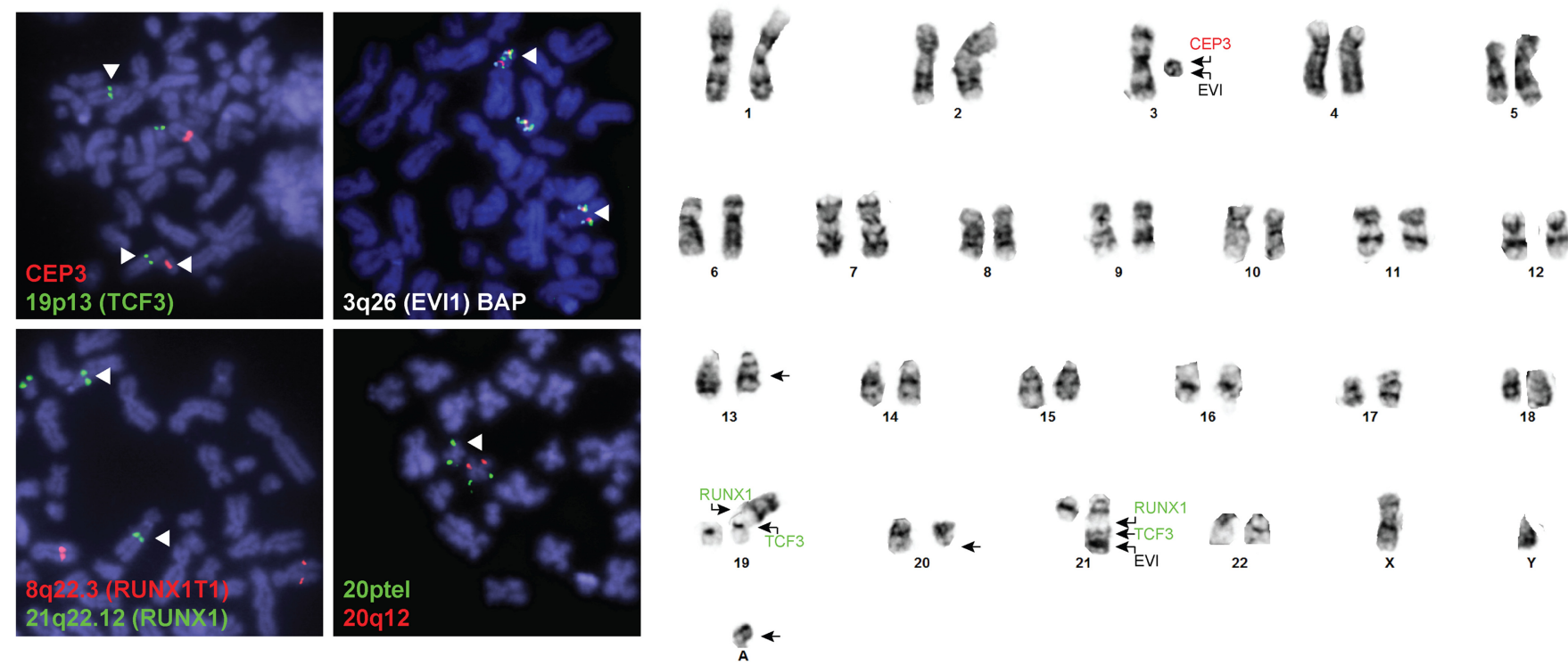

Figure 2. Complex cytogenetics observed in patient 1 . The stem line is shown on the right, which was observed in 11 of 21 cells (see Table 3 for complete nomenclature). Fluorescence in situ hybridization (FISH) studies demonstrate the ring chromosome identified by karyotype originates from Chromosome 3 and contains at least the $3 q 26$ locus (EVI1 gene). The EVI1 probe also localized to a derivative Chromosome 21, which was involved in a three-way translocation with Chromosomes 3 and 19. This was also observed with FISH for RUNX1 (21q22.12), which localized both to the derivative Chromosome 21 and a derivative Chromosome 19. Finally, a terminal deletion of $20 q$ was confirmed in $144 / 200$ interphase cells. 
A
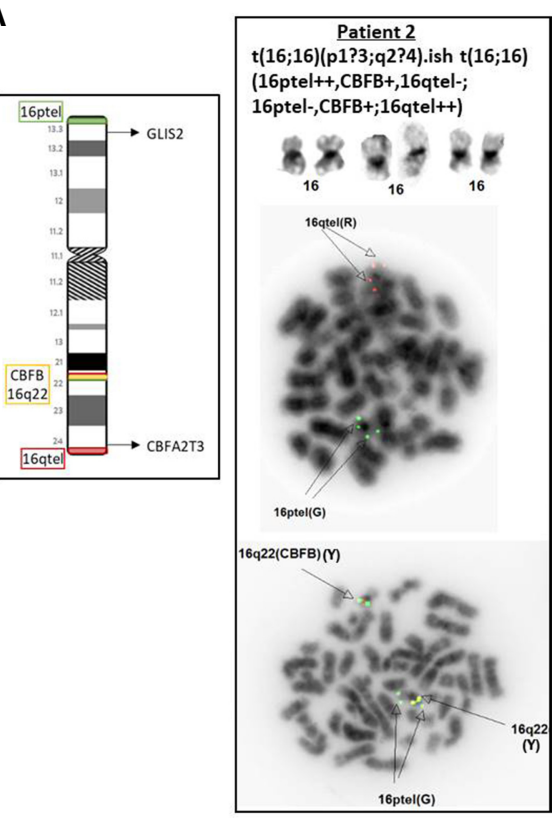

Patient 5 $(16 ; 19)(q 2 ? 4 ; q 13 . ? 1)$.ish $t(16 ; 19)$ (CBFB+,19qtel+;19ptel+,19qtel-) ish inv(16)(p?13.3q?24.3) (16qtel+, CBFB+)
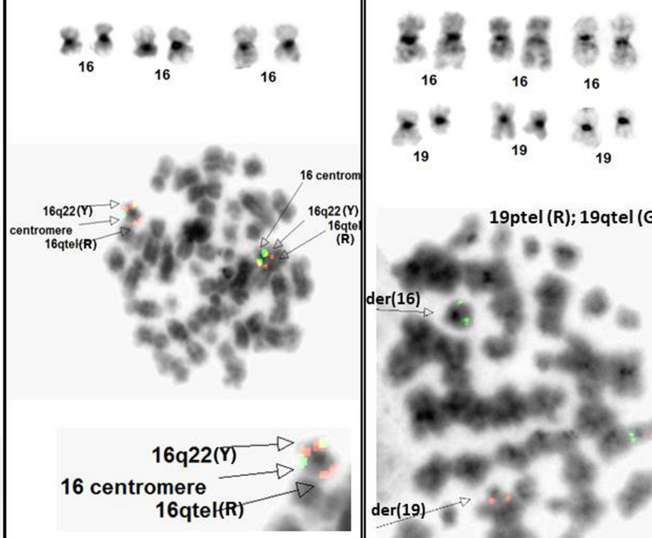

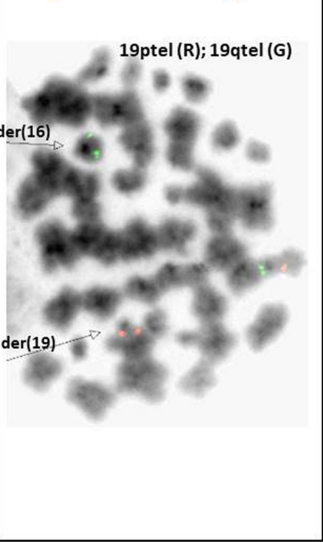

B

\begin{tabular}{|r|ccc|}
\hline Patient & Breakpoints & $\begin{array}{c}\text { Start } \\
\text { sites }\end{array}$ & $\begin{array}{c}\text { Reads } \\
\text { (\% total) }\end{array}$ \\
\hline 2 & C11G3 & 99 & $177(95.2 \%)$ \\
3 & C11G3 & 199 & $606(76.4 \%)$ \\
4 & C11G3 & 112 & $224(97.8 \%)$ \\
5 & C11G3 & 128 & $246(93.9 \%)$ \\
\hline
\end{tabular}

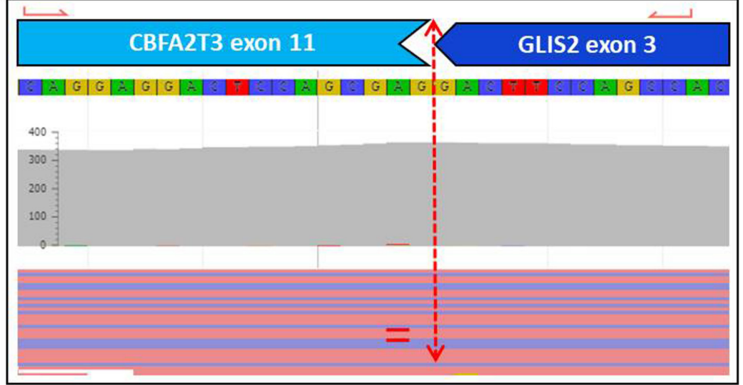

Figure 3. Diverse cytogenetic mechanisms resulting in CBFA2T3-GLIS2 gene fusions. (A) Representative cytogenetic and FISH images used to identify Chromosome 16 abnormalities in patients 2, 4, and 5. See Table 3 for complete nomenclature. Cytogenetic studies are not available for patient 3. (B) Representative screenshot from the Archer software demonstrating a CBFA2T3-GLIS2 gene fusion between exons 11 and 3 of CBFA2T3 and GLIS2, respectively (i.e., C11G3). The same breakpoint was observed in all four patients.

recurrent gene fusions, and a paucity of sequencing mutations. TAM and DS-AMKL are characterized by trisomy 21 and GATA 1 frameshift mutations with additional cytogenetic and sequence mutations observed in DS-AMKL exclusively.

\section{Genomic-Guided Management in Non-DS AMKL}

Although a diagnosis of non-DS AMKL has been historically associated with poor prognosis, these patients are clinically heterogeneous, and recent studies identified recurrent genomic changes that delineate patients into distinct prognostic groups. Inaba et al. (2015) defined three risk groups based on karyotypes, with high-risk patients having normal karyotypes, $-7,9 p$ abnormalities, including $t(9 ; 11)(p 22 ; q 23),-13 / 13 q-$, or -15 . Low-risk patients have $7 p$ abnormalities whereas the remaining patients are considered intermediate risk. More recently, recurrent gene fusions have been used to define prognosis with NUP98KDM5A, CBFA2T3-GLIS2, and KMT2A rearrangements being associated with poor prognosis, $H O X$ rearrangements and RBM15-MKL1 being associated with intermediate prognosis, 
ClinVar P/LP and HGMD DM variants:

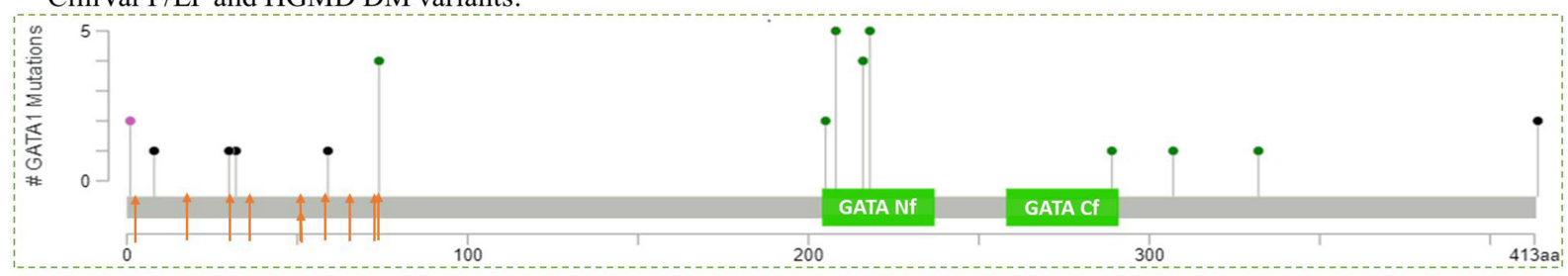

COSMIC sequence variants in hematopoietic or lymphoid tissues:

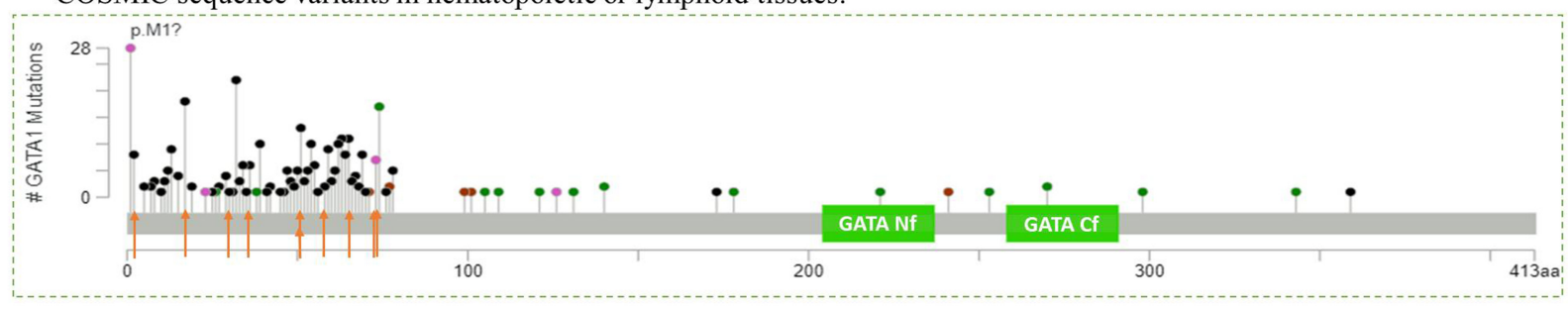

Mutation identified in this study $\quad$ Truncating mutation $\quad$ Missense mutation $\quad$ Other mutation (e.g., splicing, synonymous)

Figure 4. GATA1 variant spectrum in germline and somatic setting. The green boxes indicate the two GATA zinc finger protein domains, the amino-terminal finger ( $\mathrm{Nf}$ ) and carboxy-terminal finger (Cf). (A) GATA1 variants listed in ClinVar as Pathogenic or Likely Pathogenic or in HGMD as "disease-associated" for hereditary conditions. (B) GATA1 sequence variants listed in COSMIC identified in hematopoietic or lymphoid tissues. Intronic variants that may affect splicing are not included. Numbering based on RefSeq transcript NM_002049.3.

and GATA1 mutations being associated with good prognosis (de Rooij et al. 2016, 2017). Current risk stratification in COG is based on specific cytogenetic/molecular features, with allogenic hematopoietic stem cell transplantation (HSCT) offered during the first remission for patients with high-risk AML (Elgarten and Aplenc 2020).

The non-DS AMKL-associated gene fusions have been shown to be important drivers of leukemogenesis associated with distinct transcriptional programs and clinical outcomes (de Rooij et al. 2017). For instance, both CBFA2T3 and GLIS2 are transcriptional regulators, and the CBFA2T3-GLIS2 fusion results in increased Hedgehog, JAK-STAT, and growth factor signaling pathways leading to enhanced self-renewal of hematopoietic stem cells (Gruber et al. 2012; Thiollier et al. 2012). Interestingly, we identified this fusion in four of six patients with non-DS AMKL, indicating it may be more common than previously thought in pediatric patients, although our study is limited in size (see Study Limitations below). Our panel may have a higher detection rate for this fusion because of the open-ended polymerase chain reaction (PCR) technology used and increased sensitivity of using a targeted fusion panel as opposed to whole-transcriptome sequencing, which may be less efficient for fusions with lower expression.

In some cases, a diagnosis of AMKL cannot be achieved based on morphological or immunophenotypic information alone, and comprehensive genomic evaluation can reveal recurrent AMKL-associated mutations allowing for an integrated diagnosis of non-DS AMKL. Patients 1 and 3 did not receive a definitive diagnosis until genetic testing revealed NUP98-KDM5A and CBFA2T3-GLI3 gene fusions, respectively. Patient 1 was initially diagnosed with undifferentiated $A M L$, and upon identification of the fusion gene, his diagnosis was changed to non-DS AMKL. Additionally, the complex cytogenetic aberrations observed further confirmed a poor prognosis for this patient. For patient 3, although flow cytometry revealed megakaryocytic differentiation, he presented with a temporal sarcoma, which complicated diagnosis. Evaluation of bone marrow and correlation with genetic features 


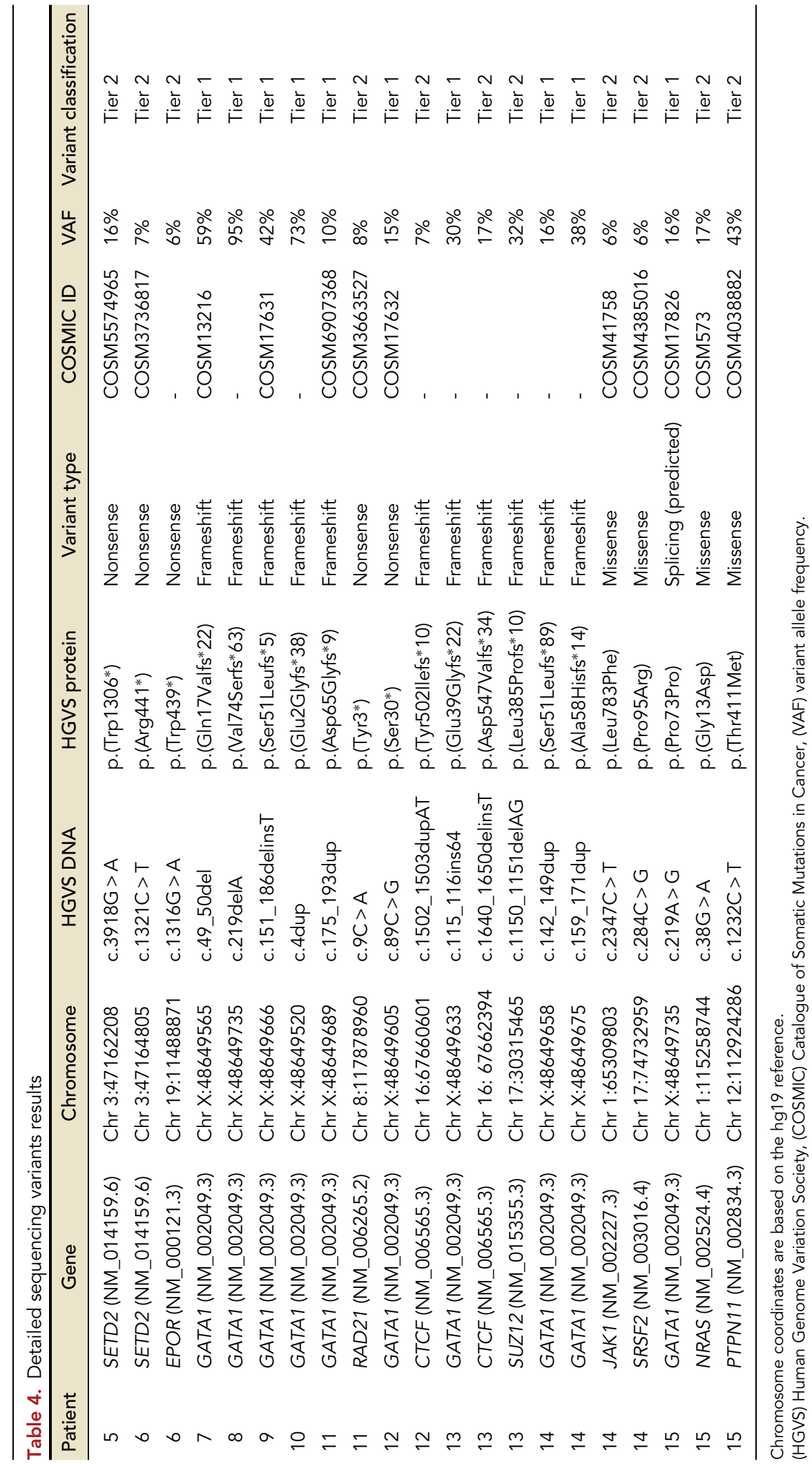


confirmed a diagnosis of non-DS AMKL. Because children with AML and NUP98 or CBFA2T3 fusions treated with chemotherapy alone have poor relapse-free survival (de Rooij et al. 2016), both patients underwent a matched unrelated donor bone marrow transplant.

\section{Significance of Genomic Evaluation in Patients with DS}

Even within DS-related myeloid malignancy, the clinical heterogeneity is striking. Despite the fact that all patients with TAM acquire GATA1 mutations, it has been estimated that up to two-thirds remain asymptomatic (i.e., silent TAM), whereas the remaining one-third ( 10\% of newborns with DS) develop clinical TAM (Roberts et al. 2013; Swerdlow et al. 2017). In most patients, TAM resolves spontaneously; however, in $20 \%-30 \%$ of patients, TAM transforms to myelodysplastic syndrome (MDS) or AML, most commonly DS-AMKL, 1-3 yr later. One theory postulates that the initiating GATA1 clone occurs in tissues of fetal hematopoiesis, which could explain the spontaneous remission observed in most patients with TAM within the first year of life, when bone marrow hematopoiesis takes over (Bhatnagar et al. 2016). If additional driver mutations arise in these clones prior to extinction of fetal hematopoiesis stem cells, there is risk of DS-AMKL. In our cohort, only one of the five patients with DS-AMKL was known to have TAM prior to their AMKL diagnosis, suggesting the remaining four had silent TAM and accumulated additional driver mutations prior to extinction of fetal hematopoiesis stem cells. Given that GATA1 is located on the X chromosome, it is interesting to note that eight of the nine patients with TAM or DS-AMKL in this cohort are male, consistent with previous studies that noted a trend toward sex bias in development of TAM/DS-AMKL (Massey et al. 2006; Heald et al. 2007). Whether the variant allele frequency of GATA1 mutations is associated with development and/or progression to DSAMKL requires additional studies.

The acquired GATA1 mutations in TAM/DS-AMKL are predominantly frameshift mutations in exon 2 (NM_002049.3), resulting in expression of a shorter isoform due to an alternative translation initiation codon at residue 84 , thereby skipping the frameshift mutations and the boundary between exon 2 and intron 2 . These mutations may be embryonic lethal as they have rarely been reported as germline changes (Rainis et al. 2003). In contrast, pathogenic germline variants in GATA1 are mostly missense mutations in exon 4 (NM_002049.3) encoding the amino-terminal zinc finger protein domain (also known as the $\mathrm{Nf}$ domain, residues 204-237 based on UniProtKB reference P15976) and are associated with X-linked anemia, neutropenia, thrombocytopenia, and platelet abnormalities, but not leukemias (Fig. 4) (Ciovacco et al. 2008).

All DS-AMKL harbored additional somatic mutations, consistent with a prior exome sequencing study showing a higher mutation burden in individuals with DS-AMKL compared to TAM (Yoshida et al. 2013). All patients with DS-AMKL had at least one additional driver mutation with an enrichment in cohesion genes, epigenetic regulators, CTCF, and other critical signaling pathway genes (Nikolaev et al. 2013; Bhatnagar et al. 2016). Here, we identify the second DS-AMKL patients with somatic mutations in SUZ12 and SRSF2, respectively (Yoshida et al. 2013). Of note, two GATA1 mutations were observed in patient 14 (DS$\mathrm{AMKL}$ ), which likely arose independently in distinct clonal populations; indeed visualization in the Integrated Genomics Viewer confirmed that these two variants were mutually exclusive. This finding is consistent with the theory that cells with trisomy 21 have a "mutator phenotype" specific to certain loci such as GATA1 (Roberts et al. 2013). In two published individuals with more than one GATA1 mutation and genetic profiling at the time of TAM and DS-AMKL diagnoses, the minor TAM subclone expanded and acquired additional mutations to become the major DS-AMKL clone (Nikolaev et al. 2013; Yoshida et al. 2013).

Identifying patients with TAM at greatest risk of DS-AMKL is not evident a priori as these patients have indistinguishable pathology at the time of initial diagnosis. The natural history 
study by the COG evaluated multiple clinical risk factors and only time to TAM resolution reached borderline significance with leukemia-free survival (Gamis et al. 2011). Of note, neither GATA1 mutation type nor diagnostic blast count is associated with progression to AMKL (Gamis et al. 2011; Bhatnagar et al. 2016). An outstanding question is whether serial, highdepth sequencing of genes involved in TAM to AMKL progression may help in early detection of DS-AMKL transformation.

\section{Importance of Comprehensive Evaluation}

Accurate and timely diagnosis and prognostication require multiple molecular and cytogenetic techniques, combining fast turnaround times with thorough evaluation. At the moment, clinical laboratories utilize various techniques to offer such comprehensive testing; however, RNA studies, which are required to detect most AMKL-related gene fusions, are not considered standard of care.

Detection of GATA1 mutations is important for diagnosis of TAM, especially "silent" TAM in which infants have a small fraction of clones with GATA1 mutations but no clinical phenotype (Roberts et al. 2013). These infants are at increased risk of developing DSAMKL. Pending studies will determine whether periodic mutation screening can improve outcomes for these infants with "silent" TAM and thus the clinical utility of screening for GATA1 mutations in all patients with DS (Roberts et al. 2013; Bhatnagar et al. 2016).

Cytogenetic evaluation can rapidly identify canonical chromosomal rearrangements associated with non-DS AMKL as well as identify prognostic structural changes. For example, a pericentric inversion of Chromosome 16 was detected with cytogenetics in the bone marrow of patient 4, strongly suggesting a CBFA2T3-GLIS2 gene fusion, which was subsequently confirmed with the NGS RNA panel. However, many of the recurrent rearrangements associated with $A M K L$ are cytogenetically cryptic and were detected using the RNA sequencing only. Indeed, despite four patients harboring the recurrent CBFA2T3-GLIS2 with standard breakpoints, only one displayed the typical cytogenetic mechanism, a pericentric inversion 16 (patient 4; Fig. 3). In the remaining two patients with this fusion with karyotype analysis, one was caused by a balanced translocation between the two Chromosome 16 homologs and the other likely involved a complex rearrangement in which only a balanced translocation between Chromosomes 16 and 19 could be observed (patient 5).

\section{Study Limitations}

One caveat to this study is the possibility of missing fusion genes involving genes of the HOX gene cluster, which are not included in the current RNA panel. However, some partner genes that have been observed in HOX fusions are included, such as EWSR1. Based on prior studies using unbiased transcriptomic profiling, it is expected that $~ 15 \%$ of patients with non-DS AMKL carry HOX rearrangements, which are associated with intermediate prognosis. Alternatively, our cohort may be biased toward patients with aggressive disease referred to the Children's Hospital of Philadelphia. This is supported by the lack of patients with genetic features associated with good (GATA1 somatic mutations) or intermediate (HOX-rearrangements and RBM15-MKL1 fusion) prognosis. Indeed, an electronic medical record search for pathological features of AMKL did not reveal any additional patients.

In summary, AMKL-related malignancies display both clinical and genomic heterogeneity. Recurrent molecular and cytogenetic changes can predict prognosis and guide management decisions. High-throughput DNA and RNA profiling is required for optimal management of AMKL-related malignancies, whereas cytogenetic studies can provide diagnostic results in a short time frame and may help to reveal underlying mechanism of genomic alterations. Thus, integrated genomic diagnostic enables personalized patient care. 


\section{METHODS}

\section{Patient Characteristics}

Patients were identified by pathological diagnosis and/or molecular findings. Comprehensive genomic evaluation using a large NGS panel for DNA and RNA has been offered at the Children's Hospital of Philadelphia since 2016. This clinical cohort was mined for patients with a pathological or molecular diagnosis of AMKL, TAM, or DS-AMKL. Specifically, the pathology reports of patients having undergone genomic profiling were mined for the words "AMKL," "megakaryoblastic," "CD41," or "CD61." Additionally, an internal genomic database was mined for clinical indications related to AMKL, TAM, or DS-AMKL and for genetic findings associated with these malignancies, including GATA1 mutations and the recurrent gene fusions observed in AMKL. This study was approved by the Institutional Review Board of the Children's Hospital of Philadelphia.

\section{Cytogenetics}

Chromosome analysis and FISH studies were performed according to standard protocols. Briefly, unstimulated bone marrow specimens were cultured and harvested after overnight incubation. G-banding metaphases were prepared using trypsin digestion followed by Giesma staining. A minimum of 20 cells were analyzed. FISH studies were performed using a panel of probes for AML and additional probes may be added based on clinical indication, where appropriate, to rule out recurrent abnormalities.

\section{NGS Panel}

The Comprehensive Hematological Cancer Panel offered by the Children's Hospital of Philadelphia Division of Genome Diagnostics (CAP-accredited) is a custom panel including sequence and copy-number analyses of 99 (version 1) to 118 (version 2) cancer genes and gene fusion detection involving one of 106 (version 1) to 110 (version 2) possible partner genes (exact number depends on date of service). The genes included in the current panel are listed at https://apps.chop.edu/service/laboratories/olsd.cfm/division-genomic-diagnostics. DNA and RNA extraction, sequencing, and analysis were performed as previously reported (Chang et al. 2019; Surrey et al. 2019). Briefly, DNA sequencing libraries are prepared from 50 ng genomic DNA using the Agilent SureSelect ${ }^{\mathrm{OXT}}$ kit, whereas RNA libraries are prepared from 150 ng input RNA or total nucleic acid using the Archer Universal RNA Reagent Kit v2. All sequencing reactions are performed with the Illumina MiSeq or HiSeq platforms with paired-end sequencing ( $2 \times 150 \mathrm{bp})$. Average sequencing coverage for the region of interest of the DNA panel is $1500 \times$ and minimum sequencing coverage is $100 \times$. See Supplemental Table 1 for sequencing and alignments metrics. In-house scripts are used to identify and annotate single nucleotide variants (SNVs) and small insertion-deletions (indels) detected within exonic regions \pm 10 bp flanking regions and intonic regions with known mutations, and copy-number variants (CNVs) are analyzed using NextGENe v2 NGS Analysis Software (Softgenetics) (Surrey et al. 2019). Gene fusions are detected using Archer Analysis according to standard protocols (Chang et al. 2019).

Somatic mutations are classified using criteria consistent with those recommended by the Association for Molecular Pathology, American Society of Clinical Oncology, and College of American Pathologists (Li et al. 2017). In brief, Tier 1 variants are actionable somatic variants with well-established evidence for diagnostic, prognostic or therapeutic implications. Tier 2 variants represent potentially actionable somatic variants. Tier 3 and 4 variants represent variants of unknown significance and likely benign/benign variants, respectively. Only Tier 1-2 variants are reported in this manuscript. Variants in GATA1 are 
COLD SPRING HARBOR Molecular Case Studies
Genomics of acute megakaryoblastic leukemia
Competing Interest Statement

M.M.L. is on the SAB of Roche Sequencing Solutions. The rest of the authors disclose no conflicts of interest.

Received December 7, 2020; accepted in revised form January 26, 2021. reported based on transcript NM_002049.3, and transcripts for remaining variants described are listed in Table 4.

\section{ADDITIONAL INFORMATION}

\section{Data Deposition and Access}

All clinically relevant variants (classified as Tier 1-Tier 3) are included in this article and its Supplemental Files. These variants were deposited to ClinVar (https://www.ncbi.nlm.nih .gov/clinvar/) and can be found under variant accession numbers RCV001293744RCV001293768. Raw data sets are not available on public databases because of lack of patient consent for data deposition (see below). Additional information is available from the corresponding author, when appropriate.

\section{Ethics Statement}

This study was approved by the Children's Hospital of Philadelphia Institutional Review Board as a retrospective analysis (IRB 17-013802). The IRB granted a waiver of consent and assent because of the retrospective nature of this study and no more than minimal risk (breach of confidentiality) to subjects. However, this waiver of consent or assent does not allow depositing full/raw data sets into publicly available databases because of risk of breach of confidentiality. This study was conducted in accordance with the Declaration of Helsinki.

\section{Acknowledgments}

The authors thank all members of the Division of Genome Diagnostics at the Children's Hospital of Philadelphia.

\section{Author Contributions}

All authors have significantly contributed to this manuscript and have read approved this submission to Cold Spring Harbor Molecular Case Studies. E.L. collected and analyzed the data and wrote the manuscript. S.R. analyzed genetic data and contributed to figures. G.W., L.F.S., F.L., X.Z., M.L., and M.M.L. analyzed genetic data. A.O. and R.A. collected data. E.L., M.L., and M.M.L. designed the study.

\section{Funding}

This work was supported by the Children's Hospital of Philadelphia.

\section{REFERENCES}

Bhatnagar N, Nizery L, Tunstall O, Vyas P, Roberts I. 2016. Transient abnormal myelopoiesis and AML in Down syndrome: an update. Curr Hematol Malig Rep 11: 333-341. doi:10.1007/s11899-016-0338-x

Chang F, Lin F, Cao K, Surrey LF, Aplenc R, Bagatell R, Resnick AC, Santi M, Storm PB, Tasian SK, et al. 2019. Development and clinical validation of a large fusion gene panel for pediatric cancers. J Mol Diagn 21: 873-883. doi:10.1016/j.jmoldx.2019.05.006

Ciovacco WA, Raskind WH, Kacena MA. 2008. Human phenotypes associated with GATA-1 mutations. Gene 427: 1-6. doi:10.1016/j.gene.2008.09.018

Creutzig U, Ritter J, Vormoor J, Ludwig W, Niemeyer C, Reinisch I, Stollmann-Gibbels B, Zimmermann M, Harbott J. 1996. Myelodysplasia and acute myelogenous leukemia in Down's syndrome. A report of 40 children of the AML-BFM Study Group. Leukemia 10: 1677-1686.

de Rooij JD, Masetti R, Van Den Heuvel-Eibrink MM, Cayuela J-M, Trka J, Reinhardt D, Rasche M, Sonneveld E, Alonzo TA, Fornerod M, et al. 2016. Recurrent abnormalities can be used for risk group stratification in 
pediatric AMKL: a retrospective intergroup study. Blood 127: 3424-3430. doi:10.1182/blood-2016-01695551

de Rooij JD, Branstetter C, Ma J, Li Y, Walsh MP, Cheng J, Obulkasim A, Dang J, Easton J, Verboon LJ, et al. 2017. Pediatric non-Down syndrome acute megakaryoblastic leukemia is characterized by distinct genomic subsets with varying outcomes. Nat Genet 49: 451-456. doi:10.1038/ng.3772

Elgarten CW, Aplenc R. 2020. Pediatric acute myeloid leukemia: updates on biology, risk stratification, and therapy. Curr Opin Pediatr 32: 57-66. doi:10.1097/MOP.0000000000000855

Gamis AS, Alonzo TA, Gerbing RB, Hilden JM, Sorrell AD, Sharma M, Loew TW, Arceci RJ, Barnard D, Doyle J, et al. 2011. Natural history of transient myeloproliferative disorder clinically diagnosed in Down syndrome neonates: a report from the Children's Oncology Group Study A2971. Blood 118: 6752-6759. doi:10 1182/blood-2011-04-350017

Gruber TA, Gedman AL, Zhang J, Koss CS, Marada S, Ta HQ, Chen SC, Su X, Ogden SK, Dang J, et al. 2012. An Inv (16)(p13. 3q24. 3)-encoded CBFA2T3-GLIS2 fusion protein defines an aggressive subtype of pediatric acute megakaryoblastic leukemia. Cancer Cell 22: 683-697. doi:10.1016/j.ccr.2012.10.007

Hama A, Yagasaki H, Takahashi Y, Nishio N, Muramatsu H, Yoshida N, Tanaka M, Hidaka H, Watanabe N, Yoshimi $A$, et al. 2008. Acute megakaryoblastic leukaemia (AMKL) in children: a comparison of $A M K L$ with and without Down syndrome. Br J Haematol 140: 552-561. doi:10.1111/j.1365-2141.2007.06971.x

Hasle H, Clemmensen IH, Mikkelsen M. 2000. Risks of leukaemia and solid tumours in individuals with Down's syndrome. Lancet 355: 165-169. doi:10.1016/S0140-6736(99)05264-2

Heald B, Hilden JM, Zbuk K, Norton A, Vyas P, Theil KS, Eng C. 2007. Severe TMD/AMKL with GATA1 mutation in a stillborn fetus with Down syndrome. Nat Rev Clin Oncol 4: 433-438. doi:10.1038/ ncponc0876

Inaba H, Zhou Y, Abla O, Adachi S, Auvrignon A, Beverloo HB, de Bont E, Chang TT, Creutzig U, Dworzak M, et al. 2015. Heterogeneous cytogenetic subgroups and outcomes in childhood acute megakaryoblastic leukemia: a retrospective international study. Blood 126: 1575-1584. doi:10.1182/blood-2015-02-629204

Li MM, Datto M, Duncavage EJ, Kulkarni S, Lindeman NI, Roy S, Tsimberidou AM, Vnencak-Jones CL, Wolff DJ, Younes A, et al. 2017. Standards and guidelines for the interpretation and reporting of sequence variants in cancer: a joint consensus recommendation of the Association for Molecular Pathology, American Society of Clinical Oncology, and College of American Pathologists. J Mol Diagn 19: 4-23. doi:10 .1016/j.jmoldx.2016.10.002

Massey GV, Zipursky A, Chang MN, Doyle JJ, Nasim S, Taub JW, Ravindranath Y, Dahl G, Weinstein HJ; Children's Oncology Group (COG). 2006. A prospective study of the natural history of transient leukemia (TL) in neonates with Down syndrome (DS): Children's Oncology Group (COG) study POG-9481. Blood 107: 4606-4613. doi:10.1182/blood-2005-06-2448

Nikolaev SI, Santoni F, Vannier A, Falconnet E, Giarin E, Basso G, Hoischen A, Veltman JA, Groet J, Nizetic D, et al. 2013. Exome sequencing identifies putative drivers of progression of transient myeloproliferative disorder to AMKL in infants with Down syndrome. Blood 122: 554-561. doi:10.1182/blood-2013-03-491936

Rainis L, Bercovich D, Strehl S, Teigler-Schlegel A, Stark B, Trka J, Amariglio N, Biondi A, Muler I, Rechavi G, et al. 2003. Mutations in exon 2 of GATA1 are early events in megakaryocytic malignancies associated with trisomy 21. Blood 102: 981-986. doi:10.1182/blood-2002-11-3599

Roberts I, Alford K, Hall G, Juban G, Richmond H, Norton A, Vallance G, Perkins K, Marchi E, McGowan S, et al. 2013. GATA1-mutant clones are frequent and often unsuspected in babies with Down syndrome: identification of a population at risk of leukemia. Blood 122: 3908-3917. doi:10.1182/blood-2013-07-515148

Roy A, Roberts I, Norton A, Vyas P. 2009. Acute megakaryoblastic leukaemia (AMKL) and transient myeloproliferative disorder (TMD) in Down syndrome: a multi-step model of myeloid leukaemogenesis. $\mathrm{Br} J$ Haematol 147: 3-12. doi:10.1111/j.1365-2141.2009.07789.x

Skucha A, Ebner J, Grebien F. 2019. Roles of SETD2 in leukemia-transcription, DNA-damage, and beyond. Int J Mol Sci 20: 1029. doi:10.3390/ijms20051029

Surrey LF, MacFarland SP, Chang F, Cao K, Rathi KS, Akgumus GT, Gallo D, Lin F, Gleason A, Raman P, et al. 2019. Clinical utility of custom-designed NGS panel testing in pediatric tumors. Genome Med 11: 32. doi:10.1186/s13073-019-0644-8

Swerdlow S, Campo E, Harris NL, Jaffe E, Pileri S, Stein H, Thiele J. 2017. WHO classification of tumours of haematopoietic and lymphoid tissues, revised 4th ed. IARC, Lyon.

Thiollier C, Lopez CK, Gerby B, Ignacimouttou C, Poglio S, Duffourd Y, Guégan J, Rivera-Munoz P, Bluteau O, Mabialah V, et al. 2012. Characterization of novel genomic alterations and therapeutic approaches using acute megakaryoblastic leukemia xenograft models. J Exp Med 209: 2017-2031. doi:10.1084/jem .20121343

Yoshida K, Toki T, Okuno Y, Kanezaki R, Shiraishi Y, Sato-Otsubo A, Sanada M, Park MJ, Terui K, Suzuki H, et al. 2013. The landscape of somatic mutations in Down syndrome-related myeloid disorders. Nat Genet 45: 1293. doi:10.1038/ng.2759 


\section{COLD SPRING HARBOR Molecular Case Studies}

\section{Clinical impact of genomic characterization of 15 patients with acute megakaryoblastic leukemia-related malignancies}

Emilie Lalonde, Stefan Rentas, Gerald Wertheim, et al.

Cold Spring Harb Mol Case Stud 2021, 7: a005975

Access the most recent version at doi: $10.1101 / \mathrm{mcs} . a 005975$
Supplementary http://molecularcasestudies.cshlp.org/content/suppl/2021/04/06/mcs.a005975.D Material C1
References This article cites 23 articles, 8 of which can be accessed free at: http://molecularcasestudies.cshlp.org/content/7/2/a005975.full.html\#ref-list-1
License This article is distributed under the terms of the Creative Commons Attribution License, which permits unrestricted reuse and redistribution provided that the original author and source are credited.
Email Alerting Receive free email alerts when new articles cite this article - sign up in the box at the Service top right corner of the article or click here.

